\title{
Decoupling liability: optimal incentives for care and litigation
}

\author{
A. Mitchell Polinsky* \\ and
}

Yeon-Koo Che**

$A$ "decoupled" liability system is one in which the award to the plaintiff differs from the payment by the defendant. The optimal system of decoupling makes the defendant's payment as high as possible. Such a policy allows the award to the plaintiff to be lowered, thereby reducing the plaintiff's incentive to sue-and hence litigation costs-without sacrificing the defendant's incentive to exercise care. The optimal award to the plaintiff may be less than or greater than the optimal payment by the defendant. The possibility of an out-of-court settlement does not qualitatively affect these results. If the settlement can be monitored, it may be desirable to decouple it as well.

\section{Introduction}

In suits between private individuals, liability is usually "coupled" in the sense that, aside from the parties' litigation costs, a successful plaintiff receives what the defendant pays. This article studies a system of "decoupled" liability - in which the plaintiff is awarded an amount different from what the defendant is made to pay. If the plaintiff is awarded less than what the defendant pays, the government obtains the difference; if the plaintiff is awarded more, the government provides the difference.

Decoupled liability already occurs in certain circumstances. For example, in several states punitive damages are decoupled, with the plaintiff receiving up to $67 \%$ of the punitive damage amount paid by the defendant (the percentage depends on the state); the rest goes to the state treasury or to a public compensation fund. ${ }^{1}$ Also, decoupled liability has been proposed in the context of private antitrust suits (see footnote 3 below).

The rationale for decoupling liability that will be investigated here is easily explained.

* Stanford University and National Bureau of Economic Research.

** University of Wisconsin, Madison.

Research on this article was supported by the John M. Olin Program in Law and Economics at Stanford Law School. Helpful comments were provided by Ian Ayres, Lucian Bebchuk, Keith Hylton, Louis Kaplow, Avery Katz, Saul Levmore, John Lott, Robert Mnookin, Ivan P'ng, Eric Rasmusen, Michael Riordan, Daniel Rubinfeld, Steven Shavell, Warren Schwartz, participants in seminars at Harvard, Stanford, and UCLA, and an anonymous referee.

'See Colo. Rev. Stat. sec. 13-21-102 (West 1988); Fla. Stat. sec. 768.73(2)-(4) (West Supp. 1991); and Iowa Code sec. 668A.1 (1)-(2) (West 1987). 
Consider any level of liability when liability is coupled. This level of liability will determine the incentive of the victim to sue (the higher the award, the greater the incentive) and the incentive of the injurer to take care. The parties' behavior in turn will determine the level of social costs-assumed to be the sum of the injurer's cost of taking care, the victim's expected harm, and the parties' expected litigation costs. ${ }^{2}$

Now consider decoupling liability, starting at the specified level of coupled liability. First raise the amount paid by the injurer, which will cause him to take more care. Then lower the amount awarded to the victim - which will reduce his incentive to sue and thereby cause the injurer to take less care-until the injurer's care is back to its level under coupled liability. Since the level of care is the same under this decoupled system and the original coupled system, so is the injurer's cost of taking care and the victim's expected harm. But since the plaintiff is awarded less under the decoupled system, he will sue less often, and consequently, litigation costs will be lower. Thus, starting from any level of coupled liability, there always exists a decoupled system of liability that reduces social costs.

This logic also can be used to establish one of the main results of the article-that in the optimal system of decoupled liability the defendant's payment is as high as possible. For if the payment by the defendant is not at its upper bound, it is possible to raise the defendant's payment and lower the plaintiff's award in such a way that the injurer's care is not affected but the parties' expected litigation costs are lowered.

With the payment by the defendant set at its upper bound, the optimal award to the plaintiff depends on how the plaintiff's award affects the injurer's care (through the plaintiff's incentive to sue) and the parties' litigation costs. It will be shown that the optimal award to the plaintiff may be less than or greater than the optimal payment by the defendant.

To understand why either relationship is possible, consider two limiting cases involving the level of harm. As the level of harm approaches zero, the optimal award to the plaintiff must approach zero; it is not worthwhile to encourage the plaintiff to sue, since the value of inducing the injurer to take care becomes small. In this case, the optimal award to the plaintiff will be less than the optimal payment by the defendant (which is at its upper bound). Conversely, as the level of harm becomes large, suits become more valuable, and it is optimal to continue to raise the award to the plaintiff. In this case, the optimal award to the plaintiff may exceed the optimal payment by the defendant.

Thus far, the discussion has assumed implicitly that all suits result in trials. In practice, however, most cases settle out of court. It will be demonstrated that the possibility of a settlement does not affect the result that the optimal payment by the defendant if the case goes to trial is as high as possible. This is for two reasons. First, as before, by making the defendant's payment as high as possible, the award to the plaintiff-and his incentive to sue-can be lowered. This will reduce either trial costs or settlement costs (which are assumed to be positive). Second, given a suit, by raising the defendant's trial payment and lowering the plaintiff's trial award, the likelihood of a settlement is enhanced because the defendant will be willing to pay more in settlement and the plaintiff will be willing to accept less. Increasing the likelihood of a settlement is beneficial because settlement costs are less than trial costs.

In addition to decoupling the trial outcome, a court sometimes may be able to monitor, and therefore decouple, the settlement. (For instance, in class action suits, settlements often have to be approved by the court.) It will be shown that if suits otherwise would not settle, it is beneficial to be able to decouple settlements because the likelihood of a settlement can thereby be increased. For example, given any decoupled trial outcome, settling can be made more attractive if the settlement amount paid by the defendant to the plaintiff is supplemented by the government.

\footnotetext{
${ }^{2}$ See generally Polinsky and Rubinfeld (1988).
} 
Section 2 introduces the basic model, in which suits are assumed to result in trials, and Section 3 derives the optimal system of decoupling in this context. Sections 4 and 5 extend the model to include settlements. Section 6 contains some concluding remarks. ${ }^{3}$

\section{The basic model}

- There is one risk-neutral injurer and many risk-neutral potential victims. The injurer chooses a level of care that affects the probability of an accident. If an accident occurs, one of the potential victims is harmed. The level of harm is fixed and the same for all potential victims. Let

$$
\begin{aligned}
c & =\text { injurer's level of care, } \\
p(c) & =\text { probability of an accident }\left(p^{\prime}<0 ; p^{\prime \prime}>0\right), \\
l & =\text { loss if an accident occurs. }
\end{aligned}
$$

Care is measured in units that cost one dollar each, so $c$ also represents the injurer's cost of care.

If the victim sues the injurer, each side bears its own legal costs. ${ }^{4}$ The injurer's cost of litigation is fixed. Each potential victim's cost of litigation also is fixed, but is assumed to vary among victims. ${ }^{5}$ This variation might be attributed, for example, to differences among individuals in the value of their time or to differences among lawyers in their fees. Let

$$
\begin{aligned}
a & =\text { potential victim's trial cost }(a>0), \\
f(a) & =\text { probability density of } a(f(a)>0 \text { for all } a>0),{ }^{6} \\
b & =\text { injurer's trial cost }(b>0) .
\end{aligned}
$$

It is assumed without loss of generality that the victim will prevail at trial if he brings a suit. The plaintiff then receives an award and the defendant makes a payment, which cannot exceed some upper bound. Let

$$
\begin{aligned}
x & =\text { award to the plaintiff at trial, } \\
y & =\text { payment by the defendant at trial, } \\
m & =\text { maximum possible payment of defendant }(y \leq m) .
\end{aligned}
$$

The defendant's payment may be bounded for any number of reasons-his limited wealth, considerations of fairness, and so forth. For purposes of our analysis, it does not matter what the bound is.

${ }^{3}$ The concept of decoupling liability was first proposed by Schwartz $(1980,1981)$ in the context of private antitrust enforcement. See also Salop and White (1986) and Polinsky (1986). Although these articles anticipated some of the results demonstrated here, they did not analyze a formal model of decoupling or systematically consider the possibility of settlements.

Several more recent articles concerned with private litigation have mentioned a decoupling-type solution. The discussion that is closest in spirit to the present analysis is by Hylton (1990). He assumes that the award to the victim equals the victim's loss and shows that the optimal payment by the injurer exceeds this amount. See also Katz (1990) and Polinsky and Shavell (1989).

${ }^{4}$ The basic ideas in this article also apply under other rules for allocating legal costs.

${ }^{5}$ Equivalently, there is one potential victim whose litigation cost is uncertain before an accident but known after an accident. (An alternative assumption that would generate similar results is that the level of harm varies among potential victims.)

${ }^{6}$ The assumption that $a$ has positive density for all positive values of $a$ is made mainly for expositional convenience; see footnote 9 below. 
If there is an accident, the victim will sue if his trial cost is less than his award at trial: $a<x .^{7}$ Thus, the probability that a suit will be brought is $F(x)$, where $F(\cdot)$ is the cumulative distribution of $a$.

The injurer chooses his level of care to minimize the sum of his cost of care, his expected payment at trial, and his expected trial cost:

$$
\underset{c}{\operatorname{MIN}} c+p(c) F(x)[y+b] .
$$

The social problem is to choose the award to the victim and the payment by the injurer that minimize the sum of the injurer's cost of care, the victim's expected harm, and the parties' expected trial costs:

$$
\operatorname{MIN}_{x, y} c+p(c)\left[l+\int_{0}^{x} a f(a) d a+F(x) b\right],
$$

where $c$ is determined by $x$ and $y$ according to (1), and $y \leq m$. The optimal values of $x$ and $y$ will be denoted $x^{*}$ and $y^{*}$; it is assumed that $x^{*}$ is positive and unique.

\section{Optimal decoupling in the basic model}

- It will first be shown that the optimal payment by the injurer at trial is as high as possible: $y^{*}=m$.

This can be proved by contradiction. Suppose that the optimal value of $y$ were $y_{0}<m$ and that the optimal value of $x$ were some $x_{0}>0$. Then, if an accident occurs, the sum of the injurer's expected payment at trial and his expected trial cost is $F\left(x_{0}\right)\left[y_{0}+b\right]$. Now raise $y_{0}$ to $m$ and lower $x_{0}$ to $x_{1}$ such that

$$
F\left(x_{0}\right)\left[y_{0}+b\right]=F\left(x_{1}\right)[m+b] .
$$

Since the expected costs borne by the injurer if there is an accident are unchanged, the injurer will choose the same level of care as before. Now observe from (2) that the injurer's cost of care and the victim's expected loss are unaffected, but that because $x$ is lower, both the victim's and the injurer's expected trial cost are reduced. Thus, the original $y_{0}$ and $x_{0}$ could not have been optimal.

Given $y^{*}=m$, the optimal award to the victim, $x^{*}$, can be determined by minimizing the objective function in (2) just over $x$, where $c$ now is determined by $x$ from

$$
\underset{c}{\operatorname{MIN}} c+p(c) F(x)[m+b]
$$

Let $c(x)$ be the solution to (4). It is easily demonstrated that $c^{\prime}>0$ ( since raising $x$ raises $F(x)$, the probability of suit).

The first-order condition that determines $x^{*}$ can be written as

$$
-p^{\prime} c^{\prime}\left[l+\int_{0}^{x} a f(a) d a+F(x) b\right]=c^{\prime}+p f(x)[x+b] .
$$

The left-hand side of (5) is the marginal benefit of raising $x$. As $x$ rises, the injurer's care increases and the probability of an accident therefore falls. This reduces the expected harm to the victim and the expected trial cost of both parties (a trial can occur only if an accident occurs). The right-hand side of (5) is the marginal cost of raising $x$, which consists of the increased care that the injurer is induced to take and the increase in the parties' expected trial costs caused by the greater likelihood that a suit will be brought if there is an accident (the increase in trial costs is $x+b$ because, for the "marginal" suit, $a=x$ ).

\footnotetext{
${ }^{7}$ There is no loss of generality in assuming that the victim will not sue if $a=x$.
} 
There is no simple relationship between $x^{*}$ and $y^{*}$. The factors that determine $x^{*}$ such as the responsiveness of the accident probability to the injurer's choice of care and the magnitude of the parties' trial costs-may have nothing per se to do with the factors that determine $y^{*}$-such as the injurer's wealth or considerations of fairness.

In general, $x^{*}$ may be less than or greater than $y^{*}$. To illustrate the former possibility, observe that $x^{*}$ must approach zero as the victim's loss, $l$, approaches zero. This can be demonstrated by contradiction. Suppose that $x^{*}$ is bounded away from zero, say by $\tilde{x}>0$. This implies some minimum level of care, say $\tilde{c}>0 .^{8}$ Thus, social costs at $x^{*}$ are at least $\tilde{c}$. Compare this to social costs when $x=0$; then, since there are no suits, $c$ is zero and social costs are simply $p(0) l$. But as $l$ approaches zero, these social costs approach zero and become less than $\tilde{c}$. Therefore, $x^{*}$ must also approach zero as $l$ approaches zero, showing that for $l$ low enough, $x^{*}<y^{*}$.

By similar reasoning, it can be demonstrated that as $l$ tends to infinity, $x^{*}$ tends to infinity. As $l$ tends to infinity, the value of taking additional care to reduce the probability of an accident increases without bound. Since $y^{*}=m$, the only way to induce the defendant to take more care is by raising $x$ so that he will be sued with a higher probability if an accident occurs. Therefore, as $l$ tends to infinity, $x^{*}$ also must tend to infinity, showing that for $l$ sufficiently large, $x^{*}>y^{*} .^{10}$

In general, $x^{*}$ is an increasing function of $l$. Thus, for accidents with relatively low losses, $x^{*}$ will be less than $y^{*}$, and for accidents with relatively high losses, $x^{*}$ will be greater than $y^{*}$.

\section{The extended model}

Now suppose that after an accident occurs, the plaintiff can make a "take-it-or-leaveit" settlement demand. ${ }^{11}$ If it is accepted by the defendant, both parties incur settlement costs (which are assumed to be less than their respective trial costs).${ }^{12}$ If it is rejected, the plaintiff then decides whether to go to trial or to drop the suit. For simplicity, both parties are assumed to have perfect information (including about each other's litigation costs). Let

$$
\begin{aligned}
s & =\text { plaintiff's settlement demand, } \\
\alpha(a) & =\text { plaintiff's settlement cost }(0<\alpha(a)<a),{ }^{13} \\
\beta & =\text { defendant's settlement cost }(0<\beta<b) .
\end{aligned}
$$

As before, a plaintiff will bring a suit if and only if $a<x$ : If $a$ is less than $x$, the plaintiff would bring a suit if it were to result in a trial; since a settlement must make him at least

\footnotetext{
${ }^{8}$ That $\tilde{c}$ must be positive can be proved by contradiction. Suppose $x^{*}>0$ and $\tilde{c}=0$. Then social welfare could be improved by setting $x=0$ (since the level of care would be the same and expected trial costs would be lower). So it must be that $c>0$ when $x^{*}>0$.

${ }^{9}$ If the trial costs of potential victims have a positive lower bound, then $x^{*}$ would tend to that lower bound as $l$ tends to zero. Assuming this lower bound is less than $y^{*}=m$, then for $l$ low enough, $x^{*}<y^{*}$, as claimed. However, if the lower bound exceeds $m$, then $x^{*}$ always would exceed $y^{*}$. (Analogous observations apply to the discussion in the next paragraph if the trial costs of victims have an upper bound.)

${ }^{10} \mathrm{~A}$ potential problem with setting $x$ greater than $y$ is that this may create an incentive for individuals to "fabricate" harms-to claim that an accident has occurred when one has not-in order to obtain the implicit government subsidy equal to $x-y$.

1 This assumption is not as special as it may appear; results qualitatively similar to those discussed in this article generally would occur if the injurer made a take-it-or-leave-it settlement offer (but see footnote 16 below).

${ }^{12}$ It will be seen that decoupling liability is always socially valuable when settlement costs are positive, whereas if settlement costs are zero, there are some circumstances in which decoupling liability is socially valuable and other circumstances in which it is not needed. The assumption that settlement costs are positive is made both to avoid the additional complexity of having to distinguish between these two sets of circumstances and because it is the more realistic assumption.

${ }^{13}$ For simplicity, $\alpha(a)$ frequently will be written as $\alpha$. It is assumed that $\alpha$ is increasing in $a$ and that $a-\alpha$ is also increasing in $a$. These assumptions would be satisfied, for example, if $\alpha$ is a constant fraction of $a$.
} 
as well off, he also would bring a suit if it were to result in a settlement. If $a$ exceeds $x$, the plaintiff would not bring a suit if it were to result in a trial. The defendant, knowing this, will reject any settlement demand; and the plaintiff will then drop the suit.

Given a suit, consider whether a settlement is feasible. If the plaintiff goes to trial, his net gain is $x-a$; if he settles, it is $s-\alpha$. Thus, the plaintiff will prefer to settle if $s-\alpha \geq x-a$ or, equivalently, $s \geq x-(a-\alpha) .{ }^{14}$ If the defendant goes to trial, his total payment is $y+b$, whereas if he settles, it is $s+\beta$. Thus, the defendant will prefer to settle if $s+\beta \leq y+b$ or $s \leq y+(b-\beta)$. Consequently, a settlement will be feasible if

$$
x-(a-\alpha) \leq y+(b-\beta) .
$$

If a settlement is feasible, a settlement will occur and will equal

$$
s=y+(b-\beta)
$$

because the plaintiff will make his take-it-or-leave-it settlement demand as high as possible. If $(6)$ does not hold, a suit will result in a trial. ${ }^{15}$

Now consider the injurer's choice of care. If a suit results in a trial, the injurer's total payment is $y+b$. If a suit results in a settlement, his total payment is $s+\beta$ or, using (7), $y+b$. (The injurer pays $y+b$ in both cases because the plaintiff's settlement demand makes the injurer indifferent between going to trial and settling.) Thus, the injurer's choice of care is determined by (1).

The social problem is essentially unchanged, except that account must be taken of expected settlement costs.

\section{Optimal decoupling in the extended model}

The principal purpose of this section is to explain why $y^{*}=m$ even when settlements are possible and why it may be desirable to decouple settlements. Since much of the logic is similar to that used previously, the discussion here will be abbreviated. Formal proofs of the main results are contained in the Appendix.

There are two natural cases to consider, depending on whether the settlement can be observed and decoupled by the court.

- Settlements cannot be decoupled. The reasoning used to show that $y^{*}=m$ in the basic model carries over with little change. If $y$ is less than $m$ and $x$ is positive, it is possible to raise $y$ and lower $x$ so that the injurer's care is held constant. As before, lowering $x$ is beneficial because it discourages costly suits (now the savings may be in the form of reduced settlement costs rather than reduced trial costs). There is an additional effect, however, in the extended model. For those suits that are still brought, raising $y$ and lowering $x$ leads to more settlements (see (6)). Since settlements are less costly than trials, this effect reinforces the result.

Given $y^{*}=m$, the optimal choice of $x$ is determined in a way similar to that discussed in the basic model. Also, the earlier observations about the relationship between $x^{*}$ and $y^{*}$ carry over essentially unchanged to the extended model. ${ }^{16}$

\footnotetext{
${ }^{14}$ There is no loss of generality in assuming that the plaintiff prefers to settle when $s=x-(a-\alpha)$. An analogous statement applies below to the defendant.

${ }^{15}$ In many recent economic models of litigation, a trial can occur only if the parties have asymmetric information. Here, even though the parties have perfect information, a trial might occur because of the decoupling of liability (when $x$ sufficiently exceeds $y$ ).

${ }^{16}$ The question arises whether it is socially desirable to discourage settlements when they cannot be decoupled, since they might undermine the effects of decoupling the trial outcome. Given the assumption that the plaintiff makes a take-it-or-leave-it settlement demand-resulting in a settlement at the upper end of the settlement range-
} 
Settlements can be decoupled. Now suppose that the court can observe the settlement amount, $s$, and award an additional amount to the plaintiff and/or make the defendant pay an additional amount. Let

$$
\begin{aligned}
& x^{\prime}=\text { additional award to the victim if there is a settlement, } \\
& y^{\prime}=\text { additional payment by the injurer if there is a settlement. }
\end{aligned}
$$

First note that, if settlements are not decoupled, some suits will result in trials if

$$
x-(a-\alpha)>y+(b-\beta)
$$

for some $a($ see $(6))$, which implies that

$$
x>y+(b-\beta) .
$$

When both the trial outcome and the settlement are decoupled, it is straightforward to show that a settlement will be feasible if

$$
x-(a-\alpha)-x^{\prime} \leq y+(b-\beta)-y^{\prime} .
$$

Since $(10)$ is equivalent to

$$
x^{\prime}-y^{\prime} \geq x-(a-\alpha)-[y+(b-\beta)],
$$

any combination of $x^{\prime}$ and $y^{\prime}$ such that

$$
x^{\prime}-y^{\prime} \geq x-[y+(b-\beta)]
$$

will satisfy (10) for all values of $a$ and will result in all suits settling.

If (9) holds, (12) implies that $x^{\prime}-y^{\prime}$ must be positive and sufficiently large. In other words, to encourage settlements when they otherwise would not occur, the government must decouple settlements in such a way as to provide a net transfer to the parties; this increases the attractiveness of a settlement relative to a trial.

It remains to be shown that it is socially desirable to decouple settlements in this way. Since the plaintiff's settlement demand will equal

$$
s=y+(b-\beta)-y^{\prime}
$$

(the right-hand side of (10)), the injurer's total payment as a result of a settlement is $s+\beta+y^{\prime}=y+b$. (The injurer's total payment does not depend on $y^{\prime}$ because the payment of $y^{\prime}$ to the government reduces the settlement amount by $y^{\prime}$.) His total payment if the case goes to trial also is $y+b$. Thus, the decoupling of settlements does not affect the injurer's incentive to take care, but it does lower litigation costs. ${ }^{17}$

Assuming $x^{\prime}$ and $y^{\prime}$ are chosen to guarantee a settlement, the reasoning used to demonstrate that $y^{*}=m$ in the basic model applies here too, except that lowering $x$ now saves settlement costs instead of trial costs.

\footnotetext{
it is not desirable to discourage settlements. In essence, this is because the injurer's incentive to take care then is not diminished by a settlement. However, if the defendant were to make a take-it-or-leave-it settlement offer, it might be desirable to discourage settlements if they cannot be decoupled.

${ }^{17}$ There is a potential detrimental effect from decoupling settlements. A victim for whom $a>x$ might nonetheless sue and then settle with the injurer in order for the parties to obtain the net transfer $\left(x^{\prime}-y^{\prime}\right)$ from the government. However, since the injurer knows that such a victim would drop the suit if the injurer rejects the victim's settlement demand, the injurer would have to be paid to settle the suit-either by the victim through a "negative" settlement $(s<0)$ or by the government through a "negative" additional payment $\left(y^{\prime}<0\right)$. Consequently, such suits can be forestalled by a policy of decoupling settlements only if the settlement amount is positive and by restricting the additional payment by the injurer to be nonnegative.
} 


\section{Concluding remarks}

- Applicability to a negligence rule. It has been assumed, implicitly, that the injurer's choice of care does not affect whether he is liable. This assumption corresponds to the rule of strict liability. A natural question is whether the analysis also applies to a negligence rule-under which the injurer is liable only if he does not take some minimum level of care, referred to as the standard of care.

In theory, it would not be necessary to decouple liability under a negligence rule. Given any standard of care, if the level of (coupled) liability for violating the standard is high enough, the injurer will meet the standard. Then the victim will not sue, since he would not prevail. Thus, the first-best level of care could be attained without any litigation costs being incurred.

In practice, however, a negligence rule is likely to lead to some suits because injurers will be found liable sometimes. An injurer may be uncertain about what the standard of care is, and therefore he may choose a level of care that leads to his being found negligent. Conversely, a court or a jury may be uncertain about what level of care was chosen by the injurer, and consequently may find him negligent.

If suits occur under a negligence rule, it is straightforward to see that the analysis of decoupling in this article applies: Whatever level of care results from the best choice of coupled liability under a negligence rule, the same level of care can be achieved with lower litigation costs by decoupling liability.

Relationship to Becker's theory of public enforcement. Our analysis of decoupling closely parallels the economic theory of public enforcement associated with Becker (1968). Becker concluded that the best system of public enforcement involves using the highest possible fine and a correspondingly low probability of detection, since such a combination can achieve any given amount of deterrence with the lowest investment in detection resources. We concluded that the best system of decoupled liability involves making the defendant's payment as high as possible so that the probability of suit can be lowered, thereby reducing litigation costs. Thus, our analysis of decoupling can be interpreted as a private litigation analogue to Becker's theory of public enforcement.

Becker's theory has been criticized on the grounds that severe fines-as high as an individual's wealth-are hardly ever imposed. An analogous criticism could be leveled against the theory of decoupled liability proposed here. In both contexts, however, there are additional considerations that could be taken into account that would lead to the conclusion that the optimal fine or the optimal payment by the defendant is not as high as possible. For example, if injurers are risk averse, it generally is desirable to reduce the sanction and to increase the probability of its imposition in order to lower risk-bearing costs.

\section{Appendix}

Statements and proofs of Propositions 1 and 2 follow.

Proposition 1. When settlements are possible but cannot be decoupled, the optimal payment by the defendant at trial is as high as possible: $y^{*}=m$.

Proof. First define $\tilde{a}(x, y) \equiv \min \{\hat{a}(x, y), x\}$, where $\hat{a}(x, y)$ solves for $a$ in

$$
x-(a-\alpha(a))=y+(b-\beta)
$$

if $x>y+(b-\beta)$, and $\hat{a}(x, y)=0$ otherwise. Since $\hat{a}(x, y)$ is increasing in $x$ and decreasing in $y$ (in the weak sense), so is $\tilde{a}$. For a plaintiff with $a<\tilde{a}$, a suit resulting in a trial occurs and litigation costs $a+b$ are incurred; for a plaintiff with $\tilde{a} \leq a<x$, a suit resulting in a settlement occurs and settlement costs $\alpha+\beta$ are incurred; and for a plaintiff with $a \geq x$, a suit does not occur.

The social problem can be written as

$$
\underset{c, x, y}{\operatorname{MIN}} c+p(c)\left[l+\int_{0}^{x}[\alpha(a)+\beta] f(a) d a+\int_{0}^{\tilde{a}(x, y)}[a-\alpha(a)+b-\beta] f(a) d a\right]
$$


subject to

$$
\begin{gathered}
c \in \operatorname{argmin} c+p(c) F(x)[y+b], \\
y \leq m .
\end{gathered}
$$

To prove that the second constraint (A4) is binding, suppose to the contrary that at the optimal choice $\left(x_{0}\right.$, $\left.y_{0}\right), y_{0}<m$. Now consider an alternative choice $\left(x_{1}, y_{1}\right)$ with $y_{0}<y_{1} \leq m$ and $F\left(x_{1}\right)\left[y_{1}+b\right]=F\left(x_{0}\right)\left[y_{0}+b\right]$. Thus, $x_{1}<x_{0}$. It follows from the construction of the new pair $\left(x_{1}, y_{1}\right)$ that the choice of the level of care $c$ remains unchanged. But the value of the objective function (expected social cost) is lower under the new pair $\left(x_{1}, y_{1}\right)$, since the first term involving an integral in (A2) is strictly increasing in $x$, and the second term involving an integral is weakly increasing in $x$ and weakly decreasing in $y$ (since $\tilde{a}$ is weakly increasing in $x$ and weakly decreasing in $y$ ).

Proposition 2. When settlements are possible and can be decoupled: (i) decoupling settlements is valuable only if some suits otherwise would not settle (i.e., only if $x>y+(b-\beta)$ ); (ii) when decoupling settlements is valuable, optimal decoupling of settlements requires a minimum net transfer to the parties from the government (at least equal to $x-[y+(b-\beta)]>0)$; (iii) the optimal payment by the defendant at trial is $y^{*}=m$.

Proof. Let $z$ denote the settlement subsidy to the two parties. (In terms of the notation of Section $5, z \equiv x^{\prime}-y^{\prime}$; the allocation of the subsidy does not matter.) To prove (i) and (ii), it suffices to show that the optimal policy involves a subsidy $z=0$ if $x \leq y+(b-\beta)$, and $z \geq x-[y+(b-\beta)]$ if $x>y+(b-\beta)$.

Analogously to the proof of Proposition 1, define $\tilde{a}(x, y, z) \equiv \min \{\hat{a}(x, y, z), x\}$, where $\hat{a}(x, y, z)$ solves for $a$ in

$$
x-(a-\alpha(a))=y+(b-\beta)+z
$$

if $x>y+(b-\beta)$, and $\hat{a}(x, y, z)=0$ otherwise. The social problem can be written as

$$
\operatorname{MIN}_{c, x, y, z} c+p(c)\left[l+\int_{0}^{x}[\alpha(a)+\beta] f(a) d a+\int_{0}^{\dot{a}(x, y, z)}[a-\alpha(a)+b-\beta] f(a) d a\right]
$$

subject to (A3) and (A4). Since $\tilde{a}$ is weakly increasing in $x$ and weakly decreasing in $y, y^{*}=m$ for the same reason as before, proving (iii).

Observe that the choice of the subsidy $z$ does not affect the level of care $c$ chosen by the injurer. Thus, if $x>y+(b-\beta)$, any $z \geq x-[y+(b-\beta)]>0$ minimizes expected social cost by letting $\tilde{a}(x, y, z)=0$; and if $x \leq y+(b-\beta)$, since $\tilde{a}=0$ anyway, $z=0$ is optimal (but not uniquely).

\section{References}

BeCKer, G.S. “Crime and Punishment: An Economic Approach.” Journal of Political Economy, Vol. 76 (1968), pp. 169-217.

$\rightarrow$ HYLTON, K.N. "The Influence of Litigation Costs on Deterrence Under Strict Liability and Under Negligence." International Review of Law and Economics, Vol. 10 (1990), pp. 161-171.

$\rightarrow \mathrm{KATZ}_{\text {; }}$ A. "The Effect of Frivolous Lawsuits on the Settlement of Litigation." International Review of Law and Economics, Vol. 10 (1990), pp. 3-27.

POLINSKY, A.M. "Detrebling versus Decoupling Antitrust Damages: Lessons from the Theory of Enforcement." Georgetown Law Journal, Vol. 74 (1986), pp. 1231-1236.

- AND RUBINFELD, D.L. "The Welfare Implications of Costly Litigation for the Level of Liability." Journal of Legal Studies, Vol. 17 (1988), pp. 151-164.

$\rightarrow$ AND SHAVELL, S. "Legal Error, Litigation, and the Incentive to Obey the Law." Journal of Law, Economics, and Organization, Vol. 5 (1989), pp. 99-108.

SALOP, S.C. AND WHITE, L.J. "Economic Analysis of Private Antitrust Litigation." Georgetown Law Journal, Vol. 74 (1986), pp. 1001-1064.

SchwarTZ, W.F. "An Overview of the Economics of Antitrust Enforcement." Georgetown Law Journal, Vol. 68 (1980), pp. 1075-1102.

. Private Enforcement of the Antitrust Laws: An Economic Critique. Washington, D.C.: American Enterprise Institute, 1981. 